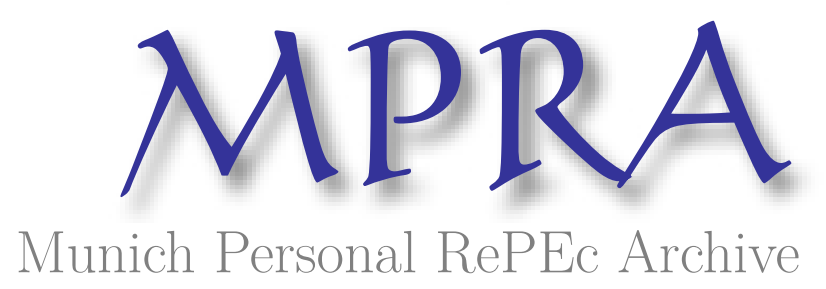

\title{
The janus face of race: Rhonda $M$. Williams on orthodox economics schizophrenia
}

Mason, Patrick L.

Florida State University

2002

Online at https://mpra.ub.uni-muenchen.de/11334/

MPRA Paper No. 11334, posted 01 Nov 2008 02:00 UTC 


\title{
THE JANUS FACE OF RACE: RHONDA M. WILLIAMS ON ORTHODOX ECONOMIC SCHIZOPHRENIA
}

\author{
Patrick L. Mason
}

\begin{abstract}
The American Negro has the great advantage of having never believed that collection of myths to which white Americans cling. ... The tendency has really been, insofar as this was possible, to dismiss white people as the slightly mad victims of their own brainwashing.

[The problem of the color line is] a fearful and delicate problem, which comprises, when it does not corrupt, all the American efforts to build a better world-here, there, or anywhere. It is for this reason that everything white Americans think they believe in must now be reexamined. - James Baldwin (The Price of the Ticket, 377-378).
\end{abstract}

Unfortunately, Baldwin is not required reading in graduate economics. "The Janus Face of Race" is the title of the introductory chapter from Race, Markets, and Social Outcomes (Mason and Williams 1997). Williams selected the title to capture the interpretative schizophrenia of orthodox economists seeking to rationalize racial inequality as a failure stemming from the behaviors and values of African-American individuals, families, and communities. Surely, Baldwin would ask whether proponents of the orthodox tradition on racial inequality and markets have become slightly mad victims of their own brainwashing?

It may be so. The empirical record certainly demonstrates a stubborn persistence in asserting black inferiority. Quoting from "The Janus Face of Race" (Mason and Williams 1997, 1), orthodox economists readily assert that.

On the one hand, race matters when the discussion is focused on anti-social behavior, social choices, and undesired market outcomes. Inexplicably, African Americans are more likely to prefer welfare, lower labor force participation, and unemployment. On the other 
hand, race does not matter when the subject of discussion is economically productive or socially acceptable activities and legal market choices (for example, [wages, employment, and education]).

Rhonda Williams and I argued that this Janus-faced construction of race is maintained by an unexamined and uncritical adherence to the market power hypothesis, which asserts that racial discrimination and market competition are inversely related. Discrimination will persist only in those areas of society where market competition is least operative. In this framework, individuals may exercise substantial discriminatory behavior in marital choice, residential location, school selection for their children, religious affiliation, organizational membership, public policy formation, and even governmental employment decisions, but, incredibly, merit is allegedly the sole determinant of economic outcomes in competitive markets.

There is an alternative perspective, one that begins with the historically validated proposition that Western capitalist societies are racialized class (and gender) formations (Williams 1983, c1944; Marable 1983; Cox 1959). Market actors learn to analyze their personal and social environment (family life, neighborhoods, religious institutions and concepts, schools, workplaces, sources of entertainment, etc.) through historically specific racial norms. These norms are the pre-and supra-market processes through which market actors develop theories, interpret data, evaluate credentials and performance, impute meaning and assess information quality, and organize and explain social structures and relations of power (Omi and Winant 1994).

For example, we might periodize U.S. racial-economic eras as follows: slavery (1619-1865), Reconstruction (1865-1877), Jim Crow (18771965), the Second Reconstruction (1954-1973), and the White Backlash (1969-present). In each era, repeated strategic interactions among market actors establish the racial-economic norms through which each actor learns to interpret and produce socioeconomic outcomes. In turn, in each era the creation and transformation of racial-economic norms is intimately related to the secular processes of capital accumulation and capitalist competition. From this perspective, agents use their own and other agents' identity claims as sources of strategic information that they can use (or attempt to use) to pursue their own self-interest (Darity, Mason, and Stewart 2002). Market and social discrimination then is not simply a matter of exogenous 'tastes;' rather, discrimination reflects a racialized economic norm that furthers racial domination. 
It is this notion of discrimination that informs a generation of heterodox theories (Baron 1971; Darity 1989; Darity and Williams 1985; Harris 1972; Mason 1993, 1995, and 1996; Swinton 1978; Williams 1987, 1991; Williams and Kenison 1996). Although differing in detail, these heterodox approaches collectively argue that discrimination is endogenous to capital accumulation and emanates from the competitive struggle for material advantage. Firms discriminate because they have the power to do so and because it increases firm profitability. Individuals form coalitions with those of similar identity to limit the competitive strength of those outside the group because they have the power to do so and because it provides material benefits. When successful, discriminators secure higher incomes, more and better jobs, superior access to health care, and privileged access to state protection and resources. Thus, the interracial distribution of wealth and power are major determinants of economic and social outcomes.

\section{EXPLANATORY POWER OF ORTHODOX AND ALTERNATIVE PERSPECTIVES}

Chart 1 captures the interpretive schizophrenia of orthodox economics. The top matrix refers to the orthodox approach, while the bottom matrix refers to the alternative approach. The rows of both matrices divide socioeconomic outcomes into two categories: desirable and undesirable. The columns of the matrices show the sign of the race effect, that is, the residual empirical correlation (after adjusting for observable differences in covariates) between African-American identity and socioeconomic outcomes. ${ }^{1}$ Each residual correlation is derived from the extant literature (see Mason and Williams 1997). For example, after adjusting for racial differences in observable productively-linked characteristics, there remains a well-established negative correlation between African-American status and income while there is a positive residual correlation between African-American identity and lower life expectancy. Hence, lower life expectancy is one of the examples in the southwest corner of each matrix, while income is one of the examples in the northeast corner of each matrix.

Orthodox interpretation is guided by three assumptions: 1) markets are generally competitive, 2) individuals are atomistic decision-makers, and 3) African Americans possess inferior unobserved attributes. ${ }^{2}$ The alternative interpretation concedes that markets are generally competitive. ${ }^{3}$ However, it assumes that a) the social identities of individuals (race, 

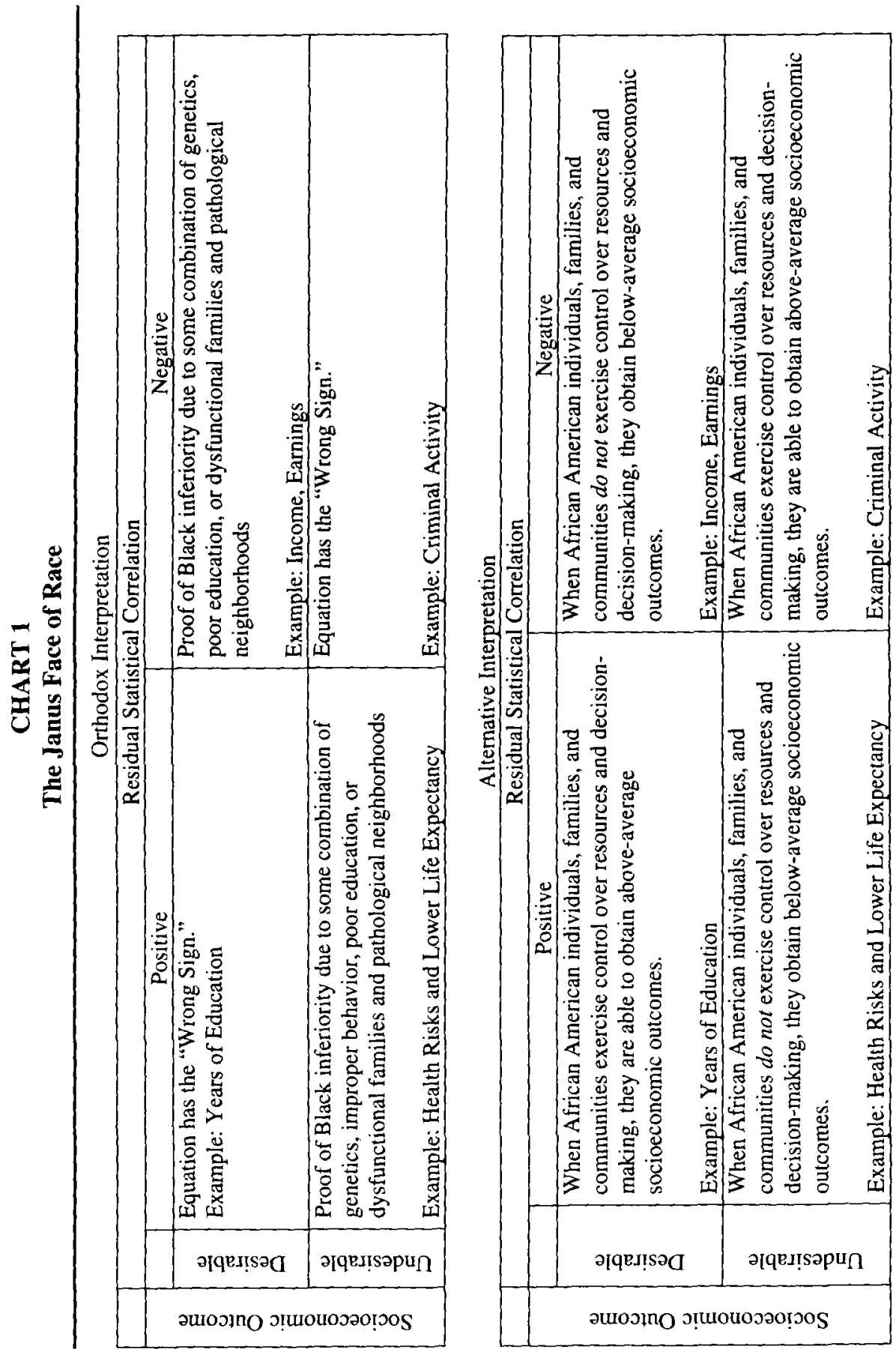
class, gender, etc.) are not divorced from market interactions; b) whites possess disproportionate social, economic, and political power; and c) there is no systematic racial pattern to the distribution of unobserved characteristics (other than the distribution of power and its concomitant control over resources and decision-making).

From the orthodox perspective, African Americans obtain lower market income because they possess inferior unobserved characteristics. The explanations for this alleged inferiority include genetic inheritance (Herrnstein and Murray 1994), inferior school quality (Ferguson 2000; Maxwell 1995) due to some combination of pre-labor market discrimination and adverse individual behavior, and other differences in family and community backgrounds (Neal and Johnson 1996). Regardless of the ultimate source-biology, non-market discrimination, individual behavior, family and community background-orthodox economists claim that after adjusting for differences in unobserved characteristics there is little if any interracial difference in market wage rates. Further, it is also argued that the lower quality or lower quantities of individual attributes explain the lower life expectancy and lower quality of health enjoyed by African Americans.

The orthodox assumption of African-American inferiority breaks down when one examines interracial differences in years of education and participation in crime. In comparison to otherwise identical whites, African Americans are able to translate a given quantity (and quality) of family resources and other observed characteristics into greater years of education and a lower supply of criminal activity.

The alternative explanation focuses on social power. When AfricanAmerican individuals, families, and communities exercise primary control over resources and decision-making, there is a positive race effect associated with desirable socioeconomic outcomes and a negative residual correlation with undesirable socioeconomic outcomes. On the other hand, when African-American individuals, families, and communities do not have primary control over resources and decision-making, there is a negative race effect associated with desirable socioeconomic outcomes and a positive residual correlation with undesirable socioeconomic outcomes.

There are substantial differences in the public policy implications of the orthodox and alternative perspectives. The essence of the orthodox approach is that racial inequality is caused by persistently inappropriate behavior that is derived from dysfunctional family values, racial culture, or community environment of African Americans. Accordingly, there is 
little that government can or should do. Government should limit itself to providing incentives for African Americans to alter their behavior or to relocate to communities with better schools and other social institutions. From the alternative perspective, persistent racial inequality is caused by persistent racial differences in access to wealth and power. Accordingly, public policy should focus on a more egalitarian distribution of wealth and power in addition to aggressive anti-discrimination measures.

\section{NON-MARKET EXAMPLE: RATE OF IMPRISONMENT}

The African-American imprisonment rate is 8.5 times the white imprisonment rate. ${ }^{4}$ Mauer (1999) reports that African Americans are 40 percent of the national prison population. Furthermore, on any given day 32 percent of African-American males ages twenty to twenty-nine are under some form of criminal justice supervision, that is, prison or jail, parole, or probation. From the orthodox perspective these racial differences are largely a reflection of inappropriate values and behaviors within African-American families and neighborhoods. Yet, the empirical evidence often shows a negative or insignificant race effect, i.e., all other things equal, African Americans are no more likely to be involved in criminal activity than otherwise identical whites. Hence, there is no prima facie evidence for the assertion that racial differences in imprisonment rates are due to racial differences in family values and behaviors.

The alternative perspective encourages us to examine how racial inequities in the criminal justice process contribute to racial differences in imprisonment rates. Chart 2 is a hypothetical representation of the decision stages of the judicial process. It assumes that there is an equally probable chance (10 percent) that African Americans and whites will commit a criminal act. Next, the chart assumes that there are relatively small differences in the probabilities of arrest, severity of charge, conviction, severity of sentence, and time served before parole or release. Beyond the individual's decision to commit a criminal act, there are five separate decisions (which produce eleven possible jail times) associated with an offense-each one of which may be affected by racial discrimination, an inability to afford competent legal council, the racially disparate impact of public policy, etc. Except for the decision to commit a criminal act, all of these decisions are outside the hand of individual African Americans and largely outside the control of the African-American community. Chart 2 reveals that relatively small differences in the individual stages of the criminal justice process can lead to dramatic 
CHART 2

Hypothetical Differences in Racial Treatment in Judicial System

\begin{tabular}{lcc}
\hline & $\begin{array}{l}\text { African } \\
\text { American }\end{array}$ & White \\
\hline Probability of Committing a Crime & 0.1000 & 0.1000 \\
Probability of Arrest & 0.9000 & 0.8000 \\
Probability of Severe Charge v. Minimal Charge & 0.4000 & 0.3000 \\
Probability of Conviction & 0.9000 & 0.8000 \\
Probability of Maximal v. Minimal Sentence & 0.5000 & 0.4000 \\
Probability of No Parole Before End of Sentence & 0.7000 & 0.6000 \\
& & \\
Probability of Being in Jail & 0.0113 & 0.0046 \\
Relative Odds of Being in Jail & & \\
\hline
\end{tabular}

differences in the probability of imprisonment. In this hypothetical example, African Americans are nearly two-and-a-half times as likely to be imprisoned as whites.

\section{MARKET EXAMPLE: EARNINGS}

Two of the more important labor market outcomes of the 1970s, 1980s, and 1990s include deterioration in the movement toward African-American/white wage equality and increasing intraracial wage inequality. Orthodox analysts suggest that skill-biased technological progress has led to a rising skill premium. In turn, the higher skill premium has led to greater inter-and intraracial earnings inequality. ${ }^{5}$ As intraracial inequality among whites increased, interracial inequality between whites and African Americans also increased because African Americans are disproportionately located in the lower half of the white skill distribution.

The racial gap in such factors as educational quality and years of education was declining throughout the 1970s, 1980s, and 1990s (Jencks, 1993:177-179; Bernstein, 1995; Ferguson, 2000). The decline in the educational quality gap would lead to a decrease in racial wage inequality, even as the rise in the rate of return to educational quality would lead to an expansion in racial wage inequality. Hence, we cannot attribute deterioration in the movement toward racial wage equality among recent labor force entrants to skill-biased technological progress unless it is further shown that the rate of return to educational quality was growing 
at a faster rate than the decline in the racial gap in educational quality. One must also demonstrate that skill-biased technological progress led to an increase in general wage inequality before the onset of the slowdown in the movement toward racial wage equality.

Suppose DW is the racial wage differential and DS is the mean racial skill differential. A very simple model of the relationship between the differentials is $D W=a D S$, where $a>0$. Hence, $d(D W) / D W=d a / a+$ $\mathrm{d}(\mathrm{DS}) / \mathrm{DS}$. Murphy and Welch (1992: 300) show that the college graduate-high school graduate wage ratio for workers with 1-5 years of experience rose from 1.30 in 1979 to 1.74 in 1989 , representing a 34 percent increase in the price of skill (da/a). This was the largest percentage increase for all experience groups. During 1980-1990, Bernstein (1995:18) shows that the racial gap in reading scores for seventeen-year-olds taking the National Assessment of Educational Progress declined by 41 percent. So, a rough estimate is $\mathrm{d}(\mathrm{DS}) / \mathrm{DS}=-0.41$ and therefore growth in the price of skill would not have been sufficient to lead to an increase in racial wage inequality. Alternative measures of skill will certainly lead to different estimates of d(DS)/DS, just as alternative studies of changes in the skill premium will produce different estimates of da/a. We raise the issue here only to demonstrate that it is one that the existing literature has passed over a bit too quickly. ${ }^{6}$

If it is also the case that the racial wage differential began to stagnate or decline before the rate of return to educational quality began to increase, then we cannot draw the conclusion that rising interracial inequality is merely a reflection of rising intraracial inequality. Indeed, the available evidence does suggest that the increase in rate of return to ability occurred after the movement toward racial equality began to stall (Mason 2000). Cawley, Heckman, and Vytlacil (1998) pinpoint the mid1980 s as the starting point of the rise in the rate of return to education. Even so, this increase in the rate of return to education occurred only for individuals in the highest ability quartile, but improvement in racial wage equality came to a halt in the early to mid-1970s.

Contradicting the notion that skill-biased technical progress has created an excess demand for skilled workers and an excess supply of less skilled workers, Pryor and Schaffer (1999) argue that the demand for low-education workers has outgrown the supply of such workers, while the demand for college-educated workers has not grown as fast as the supply of college workers. It is only the demand for college workers with high levels of educational quality that has grown faster than the supply of college degree workers with high levels of educational quality. But the 
excess demand for college degree workers with high levels of educational quality is unrelated to the nature of technological progress. Rather, it has occurred primarily because of the particularities of labor force adjustments in the health care industry and in legal services.

Pryor and Schaffer then argue that massive numbers of women entering the labor have displaced men at all levels because employers can and do pay women lower wages. Women with a college degree and high educational quality are able to displace less qualified men for high-wage jobs. Also, since workers with a college degree who do not have high levels of educational quality are in excess supply, they have begun filling jobs that have been traditionally filled by less-educated persons. Eventually, those with the lowest years and quality of education are bumped out of employment and the labor force, especially among men, and their wages decline. ${ }^{7}$

For low-education occupations, wage inequality has increased also because of a decline in real value of the minimum wage rate and a large decrease in the rate of unionization. For occupations requiring a university education, wage inequality has increased because: wages in health care and legal services have grown faster than all others, employers have replaced men with women for lower wages, technological change has increased the demand for high educational quality workers, and increase in "winner-take-all" wage setting.

An alternative line of research suggests two major factors in the relative decline of African Americans' earnings: increased discrimination, induced by greater interracial competition for income in an environment with greatly reduced anti-discrimination enforcement, and sharp reductions in the bargaining power and standard of living for all workers due to the high unemployment of the 1970s and 1980s and accompanying changes in the nature of government policy.

Consider that there was a sixteen-month inflationary recession from November 1973 to March $1975 .^{8}$ There was a six-month recession from January 1980 to July 1980 . There was another recession of sixteen months during July 1981 to November 1982. So, the one-year recovery from July 1980 to July 1981 provided only a brief pause in three years of stagnation from December 31, 1979 to December 31, 1982..$^{9}$ The Federal Reserve System (Fed) reacted to the stagflation of 1974-75 and the following years of inflation by making a fundamental change in macroeconomic policy, that is, it became much more concerned with fighting inflation than fighting unemployment. Since the African-American unemployment rate is roughly twice the national average, African Ameri- 
cans were disproportionately injured by the Fed's engineered increases in involuntary unemployment.

According to Leonard $(1991,105)$, "affirmative action under the contract compliance program virtually ceased to exist in all but name after 1980s." Leonard writes that by the mid-1980s affirmative action "no longer aided blacks." Rodgers and Spriggs (1996) also find that federal enforcement activities declined substantially in the 1980s. Accordingly, they find that contractor status made a greater contribution to firms' relative employment of nonwhite workers during the 1990s than contractor status made during 1980 s when there were major changes in the nature and behavior of the federal anti-discrimination and affirmative action machinery.

The timing of these macroeconomic and policy changes suggests that major recessions bear some responsibility for the episodic nature of changes in residual racial wage inequality. As unemployment increases and the average wage rate stagnates during periods of severe recession, job competition increases. Mason $(1995,1999)$ has argued that racial discrimination in employment is directly related to the intensity of job competition. So, as the economy enters a period of recovery and unemployment falls, residual wage inequality begins to decline. Changes in governmental policy affect the rate at which residual wage inequality is lowered during the recovery and the extent at which such inequality expands during downturns.

\section{DISCUSSION}

One clear implication of the Janus face of race is that the formation of racial norms among economists is not completely separable from the interpretation of statistical evidence on racial inequality. The racial-cultural identity of the economist informs the contextual meaning and interpretation of empirical analysis. A second point is that public policies flowing from the Janus face of race tend to reproduce racial inequality.

A third point has been mentioned but not fully discussed here. The social norms representing the collective racial-cultural identity of agents are the result of strategic behavior among agents (Darity, Mason, and Stewart 2002). Assuming that identity enters directly into an agent's maximization function and that identity also affects the rate of return to productive attributes, one can show that strategic interaction among agents can lead to racialized economic equilibria that are resistant to a wide variety of potential mutations. In particular, very unrestrictive assump- 
tions show that the economy is quite likely to move to an equilibrium characterized by bi-polar racialized identities and persistent racial wealth inequality. Hence, atomistic agents devoid of any racial, class, or gender identity do not provide the appropriate conceptual framework for understanding racial inequality. Rhonda Williams understood this long before the development of our formal model.

\section{NOTES}

1. Consider the following regression model: $y=X \beta+R \delta+\varepsilon$, where $y$ is a particular socioeconomic outcome, $\mathrm{R}$ is a dichotomous variable equal to 1 when the individual is an African American and equal 0 when the individual is white, $X$ is a vector of observed individual characteristics, and $\varepsilon$ is a random error term. The race effect, that is, the residual correlation, is captured by $\delta$.

2 . Let $\mathrm{u}$ represent the statistical effect of unobserved individual attributes. Modifying our empirical model we have $y=X \beta+R \delta+v+\varepsilon$. The orthodox argument is that $d=0$ when we have controlled for unobserved individual attributes.

3. Agreement that markets are generally competitive hardly implies agreement over theoretical conceptions of the competitive process. See Mason (1992) and the accompanying references for a discussion of this issue.

4. See http://www.sentencingproject.org/pubs/pubs.html. March 26, 2002.

5. See Darity and Mason (1998) for a detailed discussion of the extant literature.

6. Neal and Johnson (1996) is the most widely cited orthodox study. They examine a sample of individuals born after 1961 and who were no more than 18 years of age when they took the AFQT in 1980, but who were 26-29 years of age in 1990-91 when their hourly wages are observed. Wage observations less than $\$ 1.00$ per hour or more than $\$ 75.00$ per hour are deleted from their sample, while AFQT scores are both age-adjusted and standardized. They regress the mean 1990-91 log hourly wage rate against dichotomous race and ethnicity variables (black and Hispanic, respectively), AFQT, and AFQT ${ }^{2}$. The gross wage differential is -0.24 , but the residual racial wage differential from their regression is just -0.072 . This result, however, does not tell us whether the rise in the rate of return to educational quality is responsible for the deterioration in the movement toward racial inequality that set in after the mid-1970s. That is, the Neal and Johnson study does not inform us whether or not the race coefficient from a similar regression would be greater or lower if we were able to regress early 1970 s wages against pre-labor market AFQT scores.

7. Of course, the increase in job competition also increases the opportunity for racial discrimination. However, Pryor and Schaffer are not primarily interested in the issue of discrimination so this latter point is never fully explored.

8. See the National Bureau of Economic Research web page at http://www.nber.org/ cycles.html.

9. Measuring output in 1992 dollars, the gross domestic product actually moved slightly downward from $\$ 4.63$ trillion to $\$ 4.62$ trillion during the three-year interval (Dombusch, Fischer, and Startz 1998, appendix).

\section{REFERENCES}

Baron, H. "The Demand for Black Labor: Historical Notes on the Political Economy of Racism." Radical America (March-April 1971): 1-46. 
Bernstein, J. "Where's the Payoff? The Gap Between Black Academic Progress and Economic Gains." Washington, DC: Economic Policy Institute, 1995.

Cawley, John, James Heckman, and Edward Vytlacil. "Cognitive Ability and the Rising Return to Education." NBER Working Paper No. W6388, 1998.

Cox, Oliver C. Caste, Class, \& Race. New York: Monthly Review Press, 1959. Darity, Jr., William A. "What's Left of the Theory of Discrimination." In The Question of Discrimination: Racial Inequality in the U.S. Labor Market, edited by S. Shulman and William A. Darity, Jr. Middletown, CT: Wesleyan University Press, 1989.

and P. Mason. "Evidence on Discrimination in Employment: Codes of Color, Codes of Gender." Journal of Economic Perspectives 12(2) (Spring 1998): 63-90. and R. Williams. (1985). "Peddlers Forever?: Culture, Competition, and Discrimination." Papers and Proceedings of the American Economic Review 75(2) (May 1985): 256-261.

Ferguson, R. "Test-Score Trends Along Racial Lines, 1971 to 1996: Popular Culture and Community Academic Standards." In America Becoming: Racial Trends and Their Consequences, Volume I, edited by N. Smelser, W. J. Wilson, and Mitchell. Washington, DC: National Academy Press, 2000.

Harris, D. "The Black Ghetto as 'Internal Colony': A Theoretical Critique and Alternative Formulation." Review of Black Political Economy (Summer 1972): 3-33.

Herrnstein, Richard J., and Charles Murray. The Bell Curve: Intelligence and Class Structure in American Life. New York: Free Press, 1994.

Jencks, C. Rethinking Social Policy: Race, Poverty and the Underclass. New York: Harper Perennial, 1993.

Leonard, J. "The Federal Anti-Bias Effort." In Essays on the Economics of Discrimination, edited by Emily Hoffman. Kalamazoo, MI: W. E. Upjohn Institute for Employment Research, 1991.

Marable, Manning. How Capitalism Underdeveloped Black America : Problems in Race, Political Economy and Society. Boston: South End Press, 1983.

Mason, P. "Persistent Discrimination-Racial Disparity in the US, 1967-1988." American Economic Association Papers and Proceedings 90(2) (May 2000): 312-316.

. "Male Interracial Wage Differentials: Competing Explanations." Cambridge Journal of Economics 23 (May 1999): 1-39.

"Race, Culture, and Skill: Interracial Wage Differences Among African Americans, Latinos, and Whites." Review of Black Political Economy 25(3) (Winter 1997): $5-40$.

"Race, Competition and Differential Wages." Cambridge Journal of Economics 19(4) (August 1995): 545-568.

"The Divide-and-Conquer and Employer/Employee Models of Discrimination: Neoclassical Competition as Familial Defect." Review of Black Political Economy 20(4) (Spring 1992): 73-89.

Mason, P., and Rhonda Williams. Editors. Race, Markets, and Social Outcomes. Norwell, MA: Kluwer Academic Publishers, 1997.

Mauer, Mark. "The Crisis of the Young African American Male and the Criminal Justice System." Prepared for U.S. Commission on Civil Rights, Washington, DC, 1999.

Maxwell, N. "The Effect on Black-White Wage Differentials of Differences in the Quantity and Quality of Education." Industrial and Labor Relations Review 47(2) (January 1995): 249-26.

Murphy, K., and F. Welch. "The Structure of Wages." Quarterly Journal of Economics CVII (1) (February 1992): 285-326. 
Neal, D., and W. Johnson. "The Role of Pre-Market Factors in Black-White Wage Differences." The Journal of Political Economy 104 (1996): 869-895.

Omi, Michael, and Howard Winant. Racial Formation in the United States: From the 1960s to the 1990s, 2nd edition. New York: Routledge, 1994.

Pryor, F. L., and D. L. Schaffer. Who's Not Working and Why: Employment, Cognitive Skills, Wages, and the Changing US Labor Market. New York: Cambridge University Press, 1999.

Rodgers, III, W. M., and William E. Spriggs. "The Effect of Federal Contractor Status on Racial Differences in Establishment-Level Employment Shares: 19791992." American Economic Association Papers and Proceedings 86(2) (May 1996): 290-293.

Swinton, D. "A Labor Force Competition Model of Racial Discrimination in the Labor Market." Review of Black Political Economy 9(1) (Fall 1978): 5-42.

Williams, Eric. Capitalism \& Slavery. London: A. Deutsch, 1983, c1944.

Williams, R. (1991). "Competition, Discrimination and Differential Wage Rates: On the Continued Relevance of Marxian Theory to the Analysis of Earnings and Employment Inequality." In New Approaches to the Economic and Social Analysis of Discrimination, edited by R. Cornwall and P. Wunnava. New York: Praeger, 1991.

"Capital, Competition, and Discrimination: A Reconsideration of Racial Earnings Inequality." Review of Radical Political Economics 19(2) (Summer 1987): $1-15$.

Williams, R., and R. Kenison. "The Way We Were?: Discrimination, Competition, and Inter-Industry Wage Differentials in 1970." Review of Radical Political Economics 28(2) (June 1996): 1-32. 